\title{
Permeable Pavement Systems: Technical Considerations ${ }^{1}$
}

\author{
E. Bean, M. Clark, and B. Larson²
}

\section{Introduction}

Permeable pavement systems are Green Stormwater Infrastructure (GSI) practices that can reduce runoff while supporting vehicle and pedestrian traffic. Systems can be used in a wide range of applications but are most commonly sited in light duty traffic areas. This document provides technical details of permeable pavement systems, such as application, system elements, design, installation, operation, maintenance, crediting, and costs, in order to inform planners, engineers, landscape architects, local government officials, and other professionals in the built environment about the considerations for implementing and maintaining permeable pavements. For a more general overview, see the corresponding fact sheet, Permeable Pavement Systems: Overview.

Permeable pavement systems enable hydrologic function by infiltrating rainfall and contributing stormwater runoff while also supporting vehicle and pedestrian traffic. These systems can reduce pollutants discharged in runoff by infiltrating and filtering stormwater. In general, the pavement surfaces and profiles have very high infiltration rates relative to in-situ soils. This allows water to freely infiltrate into an aggregate base and/or subbase where it is stored until the volume infiltrates into the surrounding subgrade soil or discharges through an underdrain. These systems can be designed to meet stormwater management requirements for water quality and volume control in Florida. Permeable pavement systems retain particles and associated pollutants at the surface by filtering stormwater that infiltrates. However, these systems typically are less effective at removing dissolved nutrients and metals before they reach subsoils or underdrains. While permeable pavements tend to have higher costs than conventional pavements (i.e., concrete, asphalt), cost savings can be achieved by reducing or eliminating the costs for conventional stormwater infrastructure (i.e., pipes, catch basin inlets, pond areas, etc.) and increasing usable area onsite (ASCE 2015). With appropriate maintenance, permeable pavements can continue functioning for several decades, reducing runoff volumes and pollutant loadings (ASCE 2015). At the time of writing, permeable pavement systems that recover storage volume by underdrains did not receive Environmental Resource Permit credit for reducing stormwater volumes or pollutant loads in Florida.

1. This document is AE530, one of a Green Stormwater Infrastructure in Florida series of the Department of Agricultural and Biological Engineering, UF/ IFAS Extension. Original publication date April 2019. Visit the EDIS website at https://edis.ifas.ufl.edu for the currently supported version of this publication.

2. E. Bean, assistant professor, Extension specialist, Department of Agricultural and Biological Engineering; M. Clark, associate professor, Extension specialist; and B. Larson, Extension assistant scientist, Department of Soil and Water Sciences; UF/IFAS Extension, Gainesville, FL 32611.

The use of trade names in this publication is solely for the purpose of providing specific information. UF/IFAS does not guarantee or warranty the products named, and references to them in this publication do not signify our approval to the exclusion of other products of suitable composition. 


\section{Application}

Due to permeability and difference in structure, permeable pavement materials tend to have less structural strength than conventional pavements. They are most applicable to light duty traffic loadings, with infrequent heavy vehicular traffic. These settings include residential feeder streets, low-intensity commercial parking lots, roadway shoulders, pedestrian and bicycle paths, and on-street parking stalls. In addition, avoid using permeable paving materials in areas with frequent turning, as they can shift, crack, or spall (ASCE 2015).

These systems can rapidly infiltrate water through the pavement surface. However, the surface infiltration rate can diminish and result in imperviousness as sediments accumulate in the voids and clog the surface. Runoff from landscaped areas should not be directed onto permeable pavements due to the likelihood of sediment loadings. In many applications, the permeable pavement area will receive runoff from adjacent areas. These areas should be impervious and contribute limited sediment loadings to the permeable pavement surface over the life of the system.

The system should be able to drain completely within 24 to 72 hours, so poorly drained soils or low hydraulic conductivity may pose significant infiltration challenges. Also, the seasonal high-water table and any geologic confining units should be at least $2 \mathrm{ft}$ below the bottom of the system. Permeable pavement systems can be designed as detention systems with underdrains; however, this design typically does not qualify for stormwater pollutant load reduction credits. Avoid using permeable pavements where any hazardous materials may spill and contaminate soils or groundwater.

\section{System Description}

Permeable pavement systems generally have up to five material layers that make up the system: 1) permeable pavement surface material (e.g., porous asphalt, pervious concrete, concrete pavers), 2) bedding coarse, 3) choker coarse, 4) reservoir base coarse (combined base coarse and subbase reservoir layers), and 5) soil subgrade. A geotextile may also be included between the reservoir and subgrade to prevent settling of reservoir stone into the surrounding soil. Systems designed for managing stormwater runoff generally have a common profile below the pavement surface (Figure 1).

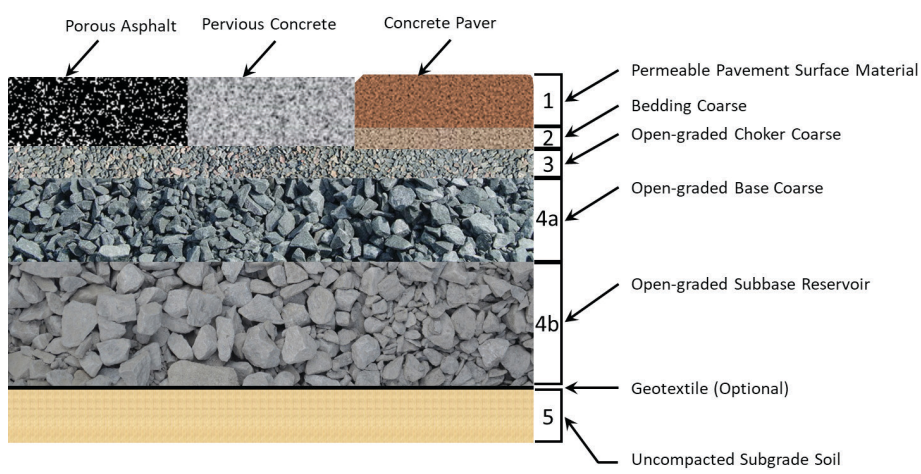

Figure 1. Typical permeable pavement cross-section profile for common pavement materials (not to scale).

Credits: Eban Bean, UF/IFAS

\section{Pavement Surface Materials}

Figure 2 shows several different types of surface materials for permeable pavement systems, including permeable interlocking concrete pavers (PICP), porous asphalt (PA), pervious (porous) concrete (PC), concrete grid pavers (CGP), and plastic reinforcing grids (PRG). For porous pavements such as PC and PA, interlocking voids are formed by omitting finer particles that are generally included in their conventional, impervious counterparts. The stone aggregates are bound together by cement or asphalt binder, but the remaining voids between the aggregates connect to allow water to flow through the porous matrix. Both PC and PA are poured and cured in place. However, porous pavers are precast pavers using mixes similar to $\mathrm{PC}$ that can be installed without needing to cure. Concrete materials (PC, PICP, and porous pavers [PP]) can also come in a range of colors.

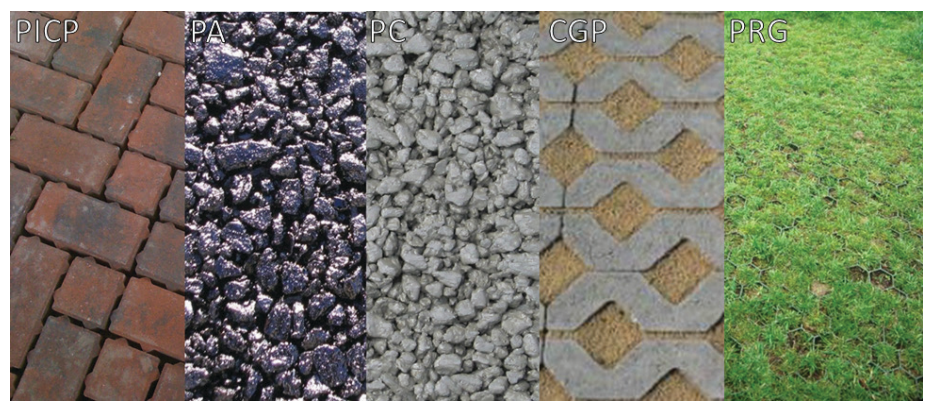

Figure 2. Common permeable pavement surface materials. Credits: Eban Bean, UF/IFAS

Other pavements such as CGP, PICP, and PRG have large voids within the pavers or form voids when installed. These voids are typically filled to the surface with a stone aggregate or a coarse sand. These voids filled with coarse material allow water to infiltrate through the pavement surface.

Surface material thicknesses will vary based on material properties and traffic loading. The thickness of PICP is typically 3 to 3.5 inches (in). PA is typically 3 to 6 in, PC is typically 4 to 8 in, and PP are typically 2 to 4 in. 


\section{Bedding Coarse}

The bedding coarse layer applies to PICP, CGP, and PP; it is not required for PC or PA. The bedding coarse is most typically an ASTM No. 8 or 89 stone coarse (3/64 to 3/8 in) (ASTM 2017), similar in size to pea gravel. The stone should be narrow or open-graded, meaning that fine sand and smaller particles have been removed from the aggregate. This is often called "washed" stone due to the use of water to flush finer particles and dust out of the aggregate. Removing the fine particles prevents them from clogging the reservoir aggregate or the surface of the subgrade soil. The depth of this layer tends to be approximately 1 in (25 $\mathrm{mm})$. With PICP or CGP, the bedding coarse aggregate will be used to fill the voids within the pavement to the surface.

Construction sand can also be used as a bedding coarse, but it should be free of fine particles and narrowly graded to allow for infiltration. Generally, this configuration is only used for CGP, and the voids are filled with the bedding sand or a topsoil and turfgrass.

\section{Choker Coarse}

The choker coarse uses an open-graded (washed) ASTM No. 57 size stone (3/16 to 1 in) (ASTM 2017), typically 3 to 6 in thick. The choker coarse blocks the void openings at the top of the reservoir coarse, preventing smaller aggregate from moving into the voids of the reservoir base below. PC and PA pavements are installed directly on top of the choker coarse.

\section{Reservoir Base Coarse}

The reservoir base coarse is constructed of an open-graded ASTM No. 2 or No. 3 stone (1 to 2.5 in) (ASTM 2017). The base coarse will commonly function as the reservoir for a permeable pavement system. While these are frequently a single layer, they may also be separate layers with a base coarse overlying a subbase reservoir (Figure 1). The thickness of this layer is determined by the structural or hydrologic design of the system. This section of the profile will provide the majority of storage for the system. Although a geotextile is not required between the reservoir coarse and the subgrade soil, it can improve structural stability of the profile by preventing migration of aggregate into surrounding soil. This geotextile should extend up the sides of the system to the pavement surface.

\section{Soil Subgrade}

The soil subgrade must have at least $2 \mathrm{in} / \mathrm{h}$ vertical saturated hydraulic conductivity when aggregate is installed. For systems designed to infiltrate into the soil subgrade, the bottom of the system should be at least $2 \mathrm{ft}$ above the seasonal high-water table. This allows the system to recover storage capacity between events by infiltrating into the available pore space within the soil subgrade.

\section{Design Considerations}

Permeable pavement design analyzes the profile depths required to meet the hydrologic and structural requirements. The greater of the two profiles is used to determine the system profile. In most settings, the hydrologic design will determine the profile depth. The pavement and bedding coarse layers have fixed thickness or depth, but the reservoir base coarse depth can be adjusted to meet the required profile design depth.

\section{Hydrologic Considerations}

The storage volume is calculated based on the thickness and porosity of the pavement system layers. Although the porosity will vary for different pavement materials, the median of the range is typically appropriate to use for design purposes. Ranges for a few pavement materials are: PC $-15 \%$ to $25 \%$; PA $-18 \%$ to $25 \%$; PICP-5\% to $15 \%$; and $\mathrm{PP}-20 \%$ to $40 \%$. Porosity values for CGP and PRG depend on the material used to fill the voids. Subbase reservoir coarse typically has a porosity of 30 to $40 \%$. Material suppliers should provide you with porosity values appropriate for the material you specify from them. These values should be used for final design.

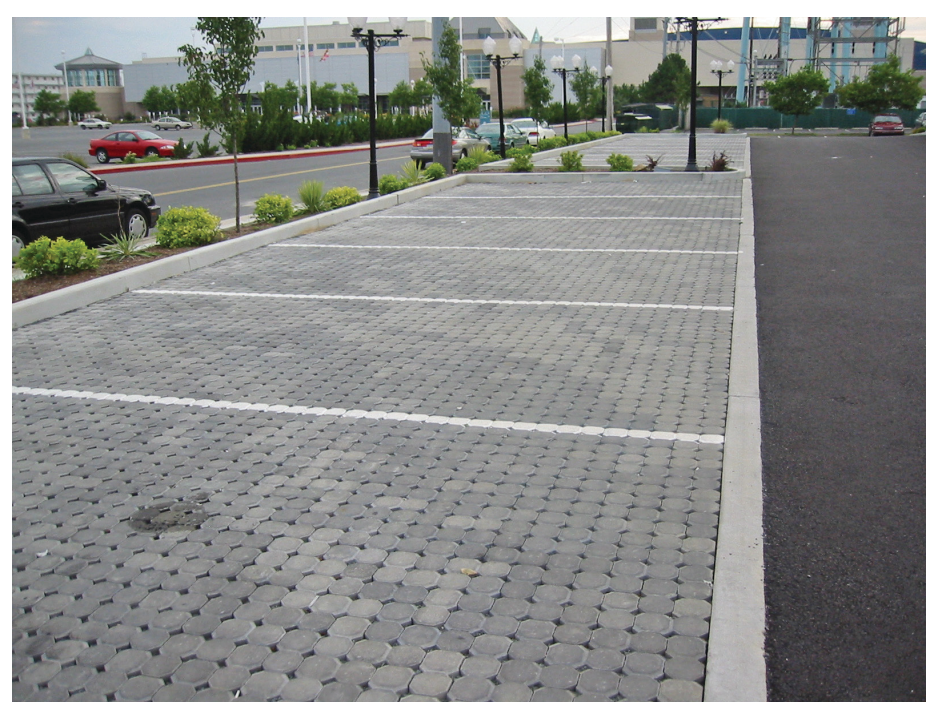

Figure 3. Newly installed PICP parking stalls as part of a commercial installation. Note the curb separating landscaping and directing runoff away from the pavement surface.

Credits: Eban Bean, UF/IFAS

If permeable pavement systems are designed for installations on slopes, they should be no steeper than $5 \%$. If steeper than $1 \%$, the system should include internal baffles 
or other measures to prevent lateral flow down the slope (ASCE 2015). If lateral flow is not restricted, it can reduce the effective retention volume of the permeable pavement system by allowing runoff to leave the system via the lowest pavement surface location.

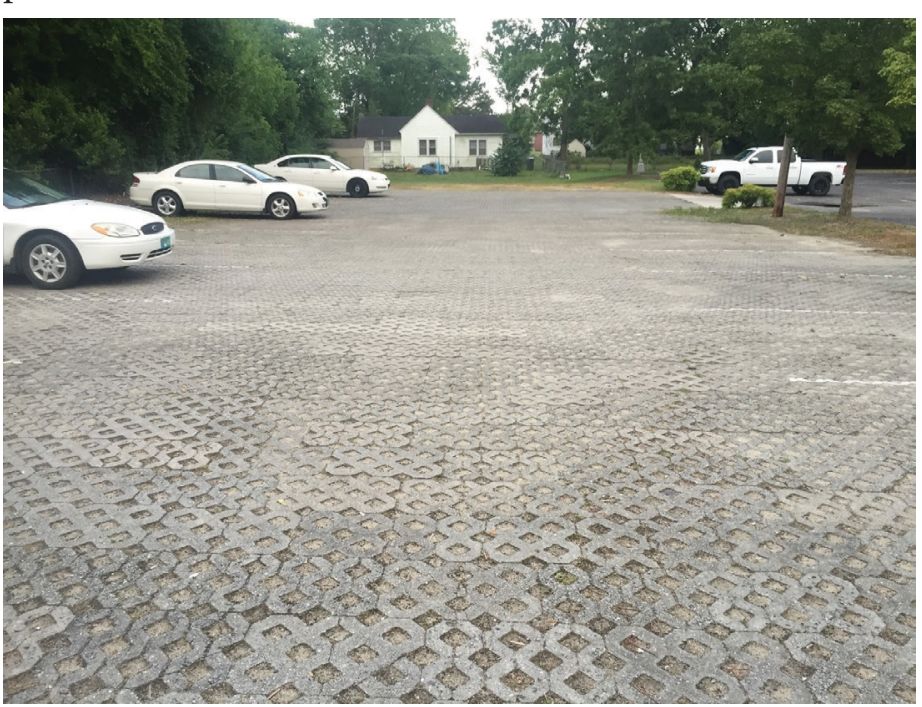

Figure 4. CGP with sand-filled voids used for a parking lot. This lot has functioned for over 20 years.

Credits: Eban Bean, UF/IFAS

Including an underdrain can facilitate recovery of storage volume at sites where infiltration is not feasible or recommended. However, pollutants may enter the drainage system via this pathway.

\section{Water Quality Considerations}

Permeable pavement systems function primarily as filters, trapping coarse solids at the surface while allowing smaller particles and dissolved pollutants to pass into the aggregate matrix below. As a result, permeable pavements can be very effective at reducing sediments and suspended particles in runoff. As particles and sediments accumulate at the surface, filtering becomes more efficient, trapping smaller and smaller particles. However, this gradually reduces the surface infiltration rate. The system needs to be maintained by removing accumulated sediments on a regular basis to restore infiltration and filtering capacities.

Subsurface aggregate layers generally offer little treatment of water quality, but instead provide storage volume while water infiltrates the subsoil or leaves through an underdrain. Thus, dissolved pollutants may infiltrate into surrounding subsoils. Activities that may release high concentrations of dissolved pollutants should not take place on or next to permeable pavements. Underdrain discharge from a permeable pavement system should be routed through a different type of stormwater control measure that is more effective at treating dissolved pollutants.

\section{Structural Considerations}

Pervious concrete systems are designed using rigid pavement design. Refer to the National Ready Mixed Concrete Association and the Portland Cement Association for design guidelines.

For PA, PICP, CGP, and PRG, a flexible pavement design approach should be used. This is most commonly the Guide for Design of Pavement Structures (AASHTO 1993) or Mechanistic-Empirical Design of New \& Rehabilitated Pavement Structures (NCHRP 2004).

\section{Installation}

Prior to installation, coordinate logistics via a preconstruction meeting with the superintendent, subcontractor foremen, permeable pavement manufacturer representative, testing lab representative, and the engineer or owner's representative. Logistical considerations should include: 1) scope and schedule, 2) test locations, 3) site access plans, including staging and construction areas, 4) quality control plans (prevention of sedimentation and compaction, material testing protocols and frequency, site inspection procedures and frequency), and 5) documentation protocols and procedures.

Avoid over-compacting subgrade soil to limit reduction of infiltration rates. Limit compacting over 92 to $95 \%$ modified Proctor density (ASTM D1557) (ASTM 2015). Immediately after excavating the reservoir, confirm that soil infiltration rates meet the design criteria. Any compaction, erosion, sedimentation, or other impacts to the reservoir should be mitigated prior to geotextile installation.

Install geotextile over the bottom of the reservoir once infiltration rates have been verified. The geotextile should extend up the sides of the reservoir to the pavement surface and be anchored approximately $1 \mathrm{ft}$ outside of the system footprint. Excess can be cut to below the pavement surface after aggregate installation.

Open-graded reservoir and base aggregate should be installed in lifts no greater than 6 in thick. Each lift should be compacted per structural design requirements. Opengraded choker coarse should also be installed in lifts up to 6 in thick and compacted to density per structural design requirements. Install open-graded bedding coarse and screed smooth to a depth of 1 in if necessary.

During installation of pavement and aggregates, measures should be in place to prevent sediment from entering the pavement areas. All stormwater runoff should be directed 
away from the pavement installation area. Sedimentation can prematurely clog the aggregate layers and pavement materials and make replacement necessary. This is particularly important to consider when working with adjacent landscaped areas that can be significant sources of sediments.

For installation of the surface pavement materials, consult the material manufacturer on appropriate procedures. Set up testing material procedures and determine delivery. Professional societies offer installation certifications for several pavement materials, such as the Interlocking Concrete Pavement Institute (ICPI) for PICP, and the National Ready Mixed Concrete Association for PC. As of 2018, the National Asphalt Pavement Association only provided webinars and information on PA installation. Use certified and experienced installers, and request examples of previous project installations to evaluate quality of work products.

All materials should be inspected as they arrive on site to ensure they meet the design specifications. For monolithic or poured-in-place pavements such as PA and PC, a test section should be created first to establish a quality standard for all future sections. Multiple test sections may be required for PA when it is produced in large batches.

Once the pavement surface is completed, it should continue to be protected from sedimentation and runoff until site disturbance is complete and adjacent areas are fully vegetated or stabilized. Covering the surface with a geotextile, tarp, or other material can protect it. This cover should be anchored and weighted down to keep it in place.

\section{Operation and Maintenance}

Clogging is the main concern with permeable pavement functioning. Siting permeable pavements in areas where they will not receive sediment-laden run-on is critical to maintaining their long-term function and limiting the need for additional maintenance. Additionally, adjacent areas should be stabilized and maintained to limit exposed soil. Organic debris, such as leaf litter and grass clippings, should also be managed to prevent decomposition and clogging. Leaves and needles should be regularly collected, and grass clippings should not be deposited on pavement surfaces.

Even with proper siting and landscape maintenance, other maintenance tasks will arise over time. Create a regular maintenance schedule to remove clogging material and limit buildup. Check with local designers or agencies for guidance on regular maintenance. An inspection checklist can help maintenance crews identify key indicators of maintenance needs. Pavement organizations (e.g., ICPI) or local agencies may have sample inspection checklists.

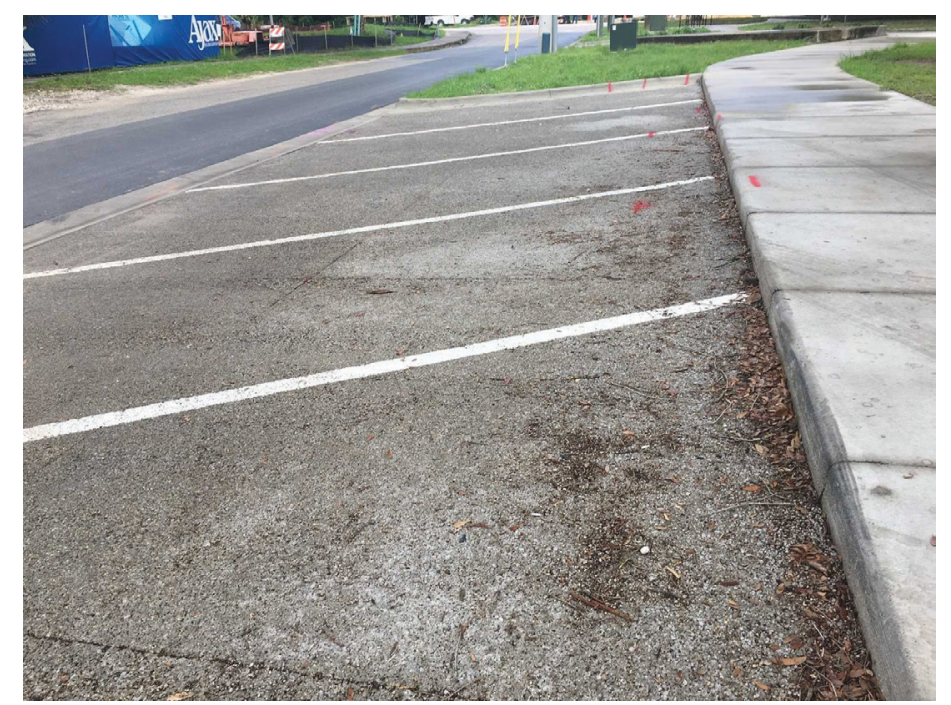

Figure 5. Porous concrete parking stalls. Note the accumulation of leaves and organic material along the curb, which can lead to surface clogging of the pavement. Clogging material should be removed regularly to maintain system performance.

Credits: Eban Bean, UF/IFAS

Including an observation well is a good practice to ensure that the permeable pavement system is properly dewatering between rainfall events. The observation well allows inspectors to determine the internal water level within the system and the potential occurrence of internal or subgrade surface clogging.

Properties can change hands. Therefore, homeowners' associations (HOAs), local governments, or other entities responsible for the long-term operation and maintenance of permeable pavements should track these pavements' locations. Utility crews should be able to easily determine where permeable pavement systems are located. This will help to avoid potential contamination or improper restoration of these systems. Local governments or property managers should inform property owners of systems on site to prevent resurfacing of permeable pavements with impermeable materials that can negate their benefits.

Including signage on site is another way to clearly indicate the presence of a permeable pavement system to owners, visitors, and maintenance crews. This can also help readers understand the way the system functions and the consequences of different activities on the site. Signage should be resilient to environmental conditions to prevent frequent replacement. 


\section{Credits in Green Building Certification Programs}

Permeable pavements can count towards several green building and related sustainability certification programs. Primarily, permeable pavement receives credit for reducing stormwater runoff, but it can also be credited for reducing heat island effect and incorporating recycled and regional aggregate materials. Below are examples of green building certification programs in which permeable pavements can qualify for particular credits, either by incorporation of the practice or by contribution to designated presumed runoff reductions based on the overall stormwater design. Always check with crediting organizations to find out the most current crediting systems available and to learn specific guidelines on receiving credit for applicable practices.

Florida-Friendly Landscaping ${ }^{\text {Ts }}$ Program (FFL)

New Construction and Large Properties

- Additional practices for commercial, institutional, and multi-family projects-Innovative stormwater treatment systems.

- First Tier-At least 50\% of hardscape surfaces are made of porous materials.

Home Landscapes

- First Tier-At least $25 \%$ of hardscape surfaces are made of porous materials.

Florida Green Building Coalition (FGBC)

Florida Green Home Standard v11

- Category 4, Site, S4 Drainage/Retention, S4.03 Maintain pervious surface area.

Florida Green Development Standard v8

- Category 1, Protection, P14 LID

- Category 2, Circulation, C8 Paving Materials

- Category 5, Covenants and Deed Restrictions, CDR3 Pervious Surfaces

Leadership in Energy and Environmental Design (LEED), US Green Building Council (USGBC)

New Construction/Homes: LEED BD+C v4 Credits

- SS Credit: Heat Island Reduction, Nonroof Measures

- SS Credit: Rainwater Management
Neighborhood Development: LEED ND v4 Credits

- Green Infrastructure and Buildings (GIB) Credit: Rainwater Management

- GIB Credit: Heat Island Reduction, Nonroof

- GIB Credit: Recycled and Reused Infrastructure

National Green Building Standard (NGBS) ICC/ASHRAE 700-2015, National Association of Home Builders (NAHB)

Single-Family New Construction

- 503.4 Stormwater Management, 3 Low Impact Development/Green Infrastructure stormwater management practices; 4 Permeable materials are used for driveways, parking areas, walkways and patios.

- 505.1 Innovative Practices, Driveways and parking areas, 4 Water permeable surfaces, including vegetative paving systems, are utilized to reduce the footprint of impervious surface driveways, fire lanes, streets or parking areas.

- 505.2 Heat island mitigation, 1c Permeable hardscaping materials are installed.

Land Development

- 403.5 Stormwater management, 3 Low Impact Development/Green Infrastructure stormwater management practices; 4 Permeable materials are used for driveways, parking areas, walkways and patios.

- 405.1 Innovative Practices, Driveways and parking areas, 4 Water permeable surfaces, including vegetative paving systems, are utilized to reduce the footprint of impervious surface driveways, fire lanes, streets or parking areas.

Sustainable Sites Initiative, American Society of Landscape Architects (ASLA)

\section{SITES v2}

- Water C3.3 Manage precipitation beyond baseline

- Soil+Veg C4.9 Reduce urban heat island effects (some permeable pavements eligible)

\section{Regulatory Considerations}

Permeable pavements designed as retention systems can receive pollutant load reduction credit to comply with the Environmental Resource Permitting program. These systems may be subject to separation from the seasonal high-water table (typically greater than $2 \mathrm{ft}$ ) as well as requirements on subgrade infiltration rates, and they may be required to have a perimeter edge restraint that forces 
ponding before overflow. Check local requirements for your project location before proceeding.

The benefits of permeable pavements to surface water quality depend primarily on infiltrating water below the surface. Therefore, regular removal of accumulated surficial sediments is important. Since underdrains can reintroduce infiltrated pollutants to the surface, underdrained permeable pavement systems do not currently receive Environmental Resource Permitting credit.

\section{Relative Costs}

Permeable pavement systems will generally cost more than conventional concrete or asphalt pavements. However, the added value is in decreasing the size of stormwater management practices on projects, increasing usable area, and reducing the need for conventional gray infrastructure, such as pipes and catch basins. Table 1 lists estimated cost ranges for pavement surface materials and system installation. These ranges are provided as an initial comparison and may not be representative of costs applicable to your location. In addition, many different factors affect the overall cost of project construction, such as area of pavement system, design requirements for regulatory compliance, distance from suppliers, soil conditions, existing condition of the site, etc. Check material prices and minimum batch or order sizes with local suppliers. Early performance of a cost analysis to evaluate the appropriateness of permeable pavement is strongly recommended.

Table 1. Estimated cost ranges for permeable pavements on a per square foot basis (ASCE 2015).

\begin{tabular}{|l|c|c|}
\hline & $\begin{array}{c}\text { Pavement } \\
\text { Surface } \\
\text { Material }\end{array}$ & $\begin{array}{c}\text { System } \\
\text { Installation }\end{array}$ \\
\hline Porous Asphalt & $\$ 2-6$ & $\$ 6-13$ \\
\hline Pervious Concrete & $\$ 2-8$ & $\$ 6-15$ \\
\hline $\begin{array}{l}\text { Permeable Interlocking Concrete } \\
\text { Pavements }\end{array}$ & $\$ 3-10$ & $\$ 7-16$ \\
\hline Concrete Grid Pavements & $\$ 3-9$ & $\$ 5-14$ \\
\hline Plastic Reinforcing Grids & $\$ 3-9$ & $\$ 5-14$ \\
\hline
\end{tabular}

\section{Conclusion}

Permeable pavement systems are a type of GSI that can treat and reduce stormwater runoff while supporting vehicle and pedestrian traffic. This publication is intended to inform technical professionals who may design, review, or maintain these systems about the design, installation, function, and maintenance of these systems. Permeable pavement systems can reduce or eliminate the need for other stormwater control measures on a site and can be adapted to meet a variety of site designs. For more information, consult additional educational and training materials offered by the professional societies (e.g., AASHTO, ASCE, NRMCA) and crediting organizations (e.g., FGBC, NAHB, USGBC) mentioned in this document. Visiting an existing installation and speaking with the designer or installer will also help you become more familiar with these systems.

\section{References}

American Association of State Highway and Transportation Officials (AASHTO). 1993. AASHTO Guide for Design of Pavement Structures. $4^{\text {th }}$ edition. Washington, D.C.: AASHTO. https://store.transportation.org/Item/ CollectionDetail? $\mathrm{ID}=86$

American Society of Civil Engineers (ASCE). 2015. Permeable Pavements. Reston, VA: ASCE Permeable Pavement Task Committee. http://www.asce.org/templates/ publications-book-detail.aspx?id=15418

American Society of Landscape Architects (ASLA). 2018. "Professional Practice: The Sustainable Sites Initiative (SITES)." Accessed on March 26, 2019. https://www.asla. org/sites/

ASTM. 2015. "D1557-12e1 Standard test methods for laboratory compaction characteristics of soil using modified effort $\left(56,000 \mathrm{ft}-\mathrm{lbf} / \mathrm{ft}^{3}\left(2,700 \mathrm{kN}-\mathrm{m} / \mathrm{m}^{3}\right)\right)$." ASTM. Accessed on March 26, 2019. https://compass.astm.org/ EDIT/html_annot.cgi?D1557+12e1

ASTM. 2017. "D448-12 Standard classification for sizes of aggregate for road and bridge construction." ASTM. Accessed on March 26, 2019. https://compass.astm.org/EDIT/ html_annot.cgi?.D448+12(2017)

Florida-Friendly Landscaping ${ }^{\text {th }}$ Program. 2018. FloridaFriendly Landscaping. Gainesville: University of Florida Institute of Food and Agricultural Sciences. https://ffl.ifas. ufl.edu/

Florida Green Building Coalition (FGBC). 2018. Florida Green Building Coalition. Accessed on March 26, 2019. http://floridagreenbuilding.org/

Interlocking Concrete Pavement Institute (ICPI). 2018. "Education." ICPI. Accessed on March 26, 2019. https:// www.icpi.org/education-certification/education 
National Association of Home Builders (NAHB). 2015.

"ICC 700 National Green Building Standard ${ }^{\mathrm{in}}$." NAHB. Accessed on March 26, 2019. https://www.nahb.org/research/ sustainability/icc-700-national-green-building-standard.

aspx

National Ready Mixed Concrete Association (NRMCA). 2018. "Pervious Concrete Contractor Certification Program.” NRMCA. Accessed on March 26, 2019. https://www. nrmca.org/Education/Certifications/Pervious_Contractor. htm

National Cooperative Highway Research Program (NCHRP). 2004. "Chapter 3. Design of New and Reconstructed Flexible Pavements." In Guide for MechanisticEmpirical Design of New and Rehabilitated Pavement Structures, Part 3: Design Analysis. Champaign, IL: National Research Council, Transportation Research Board, NCHRP. http://onlinepubs.trb.org/onlinepubs/archive/mepdg/

Part3_Chapter3_FlexibleDesign.pdf

U.S. Green Building Council (USGBC). 2018. "Leadership I Energy \& Environmental Design (LEED).” USGBC. Accessed on March 26, 2019. http://leed.usgbc.org/ 